\section{Rhinovirus-induced interferon production in asthma}

After reading the article by Sykes et al, ${ }^{1}$ we would like to comment on impaired response to rhinovirus in relation to asthma severity. The authors examined rhinovirus-induced interferon (IFN) production in a cohort of asthmatic patients compared with controls. While they previously reported in this population a reduced IFN production in cells from bronchoalveolar lavage, ${ }^{2}$ they fail to document such an impaired response in bronchial epithelial cells. ${ }^{1}$ The authors propose to ascribe such discrepancy to asthma severity, since epithelial cells successfully cultured derived from a subset of patients with milder clinical manifestations. However, (1) the authors cannot conclude on IFN production in most severe patients who were not examined in this study; (2) the cohort on the whole did not cover all the spectrum of disease severity, with most patients having mild/ moderate asthma; (3) impaired IFN production has been previously documented in epithelial cells cultured from wellcontrolled asthmatic patients. ${ }^{3} 4$

To substantiate the confinement of defective IFN production upon rhinovirus infection to the more severe expressions of the disease the authors quote their recent paper in severe therapy-resistant asthmatic children. ${ }^{5}$ However, we recently found a defective IFN induction and increased viral replication in bronchial epithelial cells of preschool children with mild asthma. ${ }^{6}$ None of the children in our report were treated with oral or high-dose inhaled corticosteroids, the majority of them receiving only inhaled rescue salbutamol. Even more compelling is our finding of similar innate immune impairments in atopic children without symptoms of asthma. Clearly, our results suggest that asthma severity is not an issue closely related with IFN responses to rhinovirus infection. Of note, we also reported that rhinovirus-induced IFN production in epithelial cells was inversely related to IL-4 expression and eosinophil counts in bronchial biopsies, suggesting that Th2 inflammatory milieu, rather than asthma severity, is tightly linked with impaired innate immune responses to rhinovirus.

Simonetta Baraldo, ${ }^{1}$ Marina Saetta, ${ }^{1}$ Angelo Barbato, ${ }^{2}$ Marco Contoli, ${ }^{3}$ Alberto Papi ${ }^{3}$

${ }^{1}$ Department of Cardiac, Thoracic and Vascular Sciences, University of Padova, Padova, Italy

${ }^{2}$ Department of Woman and Child Health, University of Padova, Padova, Italy

${ }^{3}$ Department of Medical Sciences, University of Ferrara, Ferrara, Italy

Correspondence to Dr Simonetta Baraldo, Department of Cardiological, Thoracic and Vascular Sciences Respiratory Diseases Clinic, University of
Padova, Via Giustiniani 3, Padova 35128, Italy; simonetta.baraldo@unipd.it

Contributors $S B, M S, A B, M C$ and $A P$ conceived and drafted this manuscript.

Funding Work supported by the Universities of Padova and Ferrara and the Italian Society of Pediatric Respiratory Diseases.

Competing interests None.

Provenance and peer review Not commissioned; internally peer reviewed.

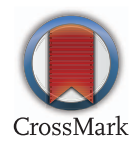

To cite Baraldo S, Saetta M, Barbato A, et al. Thorax 2014;69:772.

Received 28 November 2013

Revised 12 March 2014

Accepted 13 March 2014

Published Online First 2 April 2014

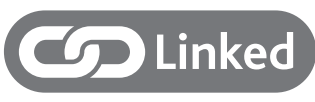

http://dx.doi.org/10.1136/thoraxjnl-2012-202909

Thorax 2014;69:772.

doi:10.1136/thoraxjnl-2013-204922

\section{REFERENCES}

1 Sykes A, Macintyre J, Edwards MR, et al. Rhinovirusinduced interferon production is not deficient in well controlled asthma. Thorax 2014;69:240-6.

2 Sykes A, Edwards MR, Macintyre J, et al. Rhinovirus 16 -induced IFN- $\alpha$ and IFN- $\beta$ are deficient in bronchoalveolar lavage cells in asthmatic patients. J Allergy Clin Immunol 2012;129:1506-14.

3 Wark PAB, Johnston SL, Bucchieri F, et al. Asthma0tic bronchial epithelial cells have a deficient innate immune response to infection with rhinovirus. J Exp Med 2005;201:937-47.

4 Contoli M, Message SD, Laza-Stanca V, et al. Role of deficient type III interferon-lambda production in asthma exacerbations. Nat Med 2006;12:1023-6.

5 Edwards MR, Regamey N, Vareille M, et al. Impaired innate interferon induction in severe therapy resistant atopic asthmatic children. Mucosal Immunol 2013:6:797-806.

6 Baraldo S, Contoli M, Bazzan E, et al. Deficient antiviral immune responses in childhood: distinct roles of atopy and asthma. J Allergy Clin Immunol 2012;130:1307-14. 